\section{Kidney \\ Blood Pressure Research}

\title{
Study of the True Clinical Progression of Autosomal Dominant Alport Syndrome in a European Population
}

\author{
Consolación Rosado ${ }^{a, b} \quad$ Elena Bueno ${ }^{a, c} \quad$ Carmen Felipe $^{b} \quad$ Sebastián Valverde $^{d}$ \\ Rogelio González-Sarmiento ${ }^{a, c}$
}

a Molecular Medicine Unit, Department of Medicine, University of Salamanca, Salamanca; ${ }^{b}$ Nephrology Unit, Care Complex of Ávila, SACYL, Ávila; 'IBSAL and IBMCC, University of Salamanca, CSIC and SACYL, Salamanca; ${ }^{d}$ Department of Urology, University Hospital, SACYL, Salamanca, Spain

\section{Key Words}

Alport syndrome • COL4A3 • COL4A4 • Autosomal dominant inheritance

\begin{abstract}
Background/Aims: Autosomal dominant Alport syndrome represents $5 \%$ of all Alport syndrome cases. This entity presents a different clinical expression from the recessive inheritance pattern and the $X$ chromosome-linked pattern, because it is mild and it shows a late onset, which in many cases even goes unnoticed. Methods: We carried out a descriptive observational and retrospective clinical study on 19 patients from 5 families with a clinical diagnosis of autosomal dominant Alport Syndrome, and we analyzed the expression of the symptoms in the different families, comparing the results with what has been described in the literature. Results: Renal involvement appeared at a young age, with a progression towards end-stage chronic kidney disease at a median age of 31 years (20.5-36.5). Hearing involvement also appeared in early stages, at a median age of 28.5 years (7.5-62.5). Also, we observed ocular lenticonus-like injuries, which until now have only been described in other inheritance patterns. Conclusions: Our results suggest that dominant patterns are accompanied by a severe clinical expression that can be superimposed to the recessive and $\mathrm{X}$ chromosomelinked patterns, contrary to what has been classically stated. The high phenotypic variability observed in the families lead to the fact that many cases go unnoticed and the severest cases are erroneously diagnosed as recessive, which means that the real prevalence of dominant forms is probably higher than the current $5 \%$.
\end{abstract}

Copyright $@ 2015$ S. Karger AG, Basel

\section{Introduction}

Autosomal dominant Alport syndrome (OMIM 104200) represents 5\% of all cases of Alport syndrome and, with benign familial haematuria and the state of carrier of autosomal recessive Alport syndrome, it makes up the entity called "collagen type IV ( $\alpha 3-\alpha 4)$ 


\section{Kidney \\ Blood Pressure Research}

Kidney Blood Press Res 2015;40:435-442

\begin{tabular}{l|l}
\hline DOI: $10.1159 / 000368519$ & (c) 2015 S. Karger AG, Basel
\end{tabular}

Published online: July 31, 2015

www.karger.com/kbr

Rosado/Bueno/Felipe/Valverde/González-Sarmiento: True Clinic of Autosomal Dominant Alport Syndorme

nephropathy" [1]. These entities are caused by mutations in the COL4A3 and COL4A4 genes, which are responsible for the synthesis of the $\alpha 3$ and $\alpha 4$ chains of the collagen IV network. Such mutations alter the production and assembly of this network, which is an essential component in the structure of the glomerular basement membrane of the kidney, the inner ear and the eye $[1,2]$.

Unlike the recessive and X chromosome-linked patterns, where a severe phenotype can be observed, in the few cases with a dominant pattern, the clinical evolution is less aggressive, the renal symptoms (haematuria and proteinuria) appear at later stages of life, with a slow evolution towards chronic kidney failure which, in very few cases, reaches an end-stage chronic kidney failure [3,4]. Hearing loss in these cases is also mild and it also appears at adult age.

Lenticonus and maculopathy are the most common ocular injuries in recessive and $\mathrm{X}$ chromosome-linked Alport syndrome. However, in dominant cases, retinopathy and cataracts are the only anomalies that have been described [5]. In spite of these common features, there is a high intra-familial phenotypic variability, which is responsible for the fact that no correlations between genotype and phenotype can be established in this inheritance pattern [1]. The low prevalence of dominant cases can be partly due to under diagnoses because, when the phenotype is mild, they can go unnoticed. However, they deserve special attention, because, in some patients, the renal involvement may lead to end-stage chronic kidney disease [3].

In our study we analyze the clinical and phenotypic aspects of the population who has been diagnosed with autosomal dominant Alport syndrome in our hospital in the period 2000-2013, and we compare the results with those of other published series, in order to establish whether the clinical evolution of our patients matches what has been described in the literature.

\section{Patients and Methods}

We have carried out a descriptive, observational and retrospective clinical study, in which we have reviewed the clinical record of the patients who were diagnosed with autosomal dominant Alport syndrome and required medical assistance in the department of Nephrology of our hospital in the period 2000-2013.

The diagnosis of Alport syndrome was established when the index patient met at least two of the following criteria [6-8]:

- Positive family record of macro or microscopic hematuria with or without progression to end-stage chronic kidney disease.

- Progressive sensorineural deafness for high tones.

- Characteristic ocular manifestations (lenticonus or maculopathy).

- Compatible renal biopsy findings (laminated glomerular basement membrane).

In the group of patients who met those criteria, we selected those who presented an autosomal dominant inheritance pattern, in which we made an analysis of the COL4A3 and COL4A4 by heteroduplex with acrylamide gels, to detect the presence of mutations in exon regions and flanking intronic secuences. PCR fragments showing anomalous migration patterns in that analysis were sequenced on an ABI 3100 genetic analyser in order to find out any pathogenic mutation in these genes, that could confirm the diagnosis of Alport syndrome [9].

In each selected case, we analyzed the clinical and demographic parameters, including sex, family record (with the possible existence of consanguinity), haematuria, proteinuria, hypertension, hearing loss, compatible ocular impairment or chronic kidney disease. We also recorded the degree and age of appearance of these signs and whether they were present at the moment of the clinical diagnosis of the disease. 


\section{Kidney Blood Pressure Research}

Kidney Blood Press Res 2015;40:435-442

\begin{tabular}{l|l}
\hline DOI: 10.1159/000368519 & (C) 2015 S. Karger AG, Basel
\end{tabular}

Published online: July 31, 2015

www.karger.com/kbr

Statistical method

We carried out a retrospective, descriptive and observational study in which we used the SPSS 20.0 software pack for Mac OS X. Qualitative variables are expressed as percentages, whereas quantitative ones are expressed as a median and interquartile range.

\section{Results}

The study included 19 patients from 5 families with a diagnosis of autosomal dominant Alport syndrome. In this group, 9 of them were men (47.4\%) and 10 were women (52.6\%).

\section{Family 1}

We studied 10 patients, who shared the pathogenic mutation c.345 delG; p.G115GfsX37 in the COL4A3 gene [10]. The study of the COL4A4 gene did not show any pathogenic mutation.

The index case (patient 7858 of the Figure 1) is a 48 years old Caucasian Spanish woman, who has suffered multiple crises of microscopic haematuria, spontaneously or after febrile episodes since she was 2 years old. At the age of 32 , she was diagnosed with hypertension, proteinuria (1.92 g/day) and chronic kidney disease (glomerular filtration rate $45 \mathrm{ml} / \mathrm{min}$ ). At 46 years old, she was diagnosed with high tones bilateral hearing loss. Her son suffered from sporadic crises of macroscopic and microscopic haematuria and proteinuria $(2.2 \mathrm{~g} / 24 \mathrm{~h})$ since he was 6 years old and, 3 years later, he was diagnosed with high tones sensorineural hearing loss and anterior lenticonus. At the age of 19, he developed chronic kidney disease, which evolved into the need for renal replacement therapy three years later. The patient never developed hypertension.

The rest of the affected family members only suffer high tones bilateral sensorineural hearing loss, without haematuria or impaired kidney function.

\section{Family 2}

There were 3 affected patients, who shared the pathogenic mutation c.4235G $>\mathrm{T}$; p.G1412V of the COL4A3 gene [1]. There were no pathogenic mutations in the COL4A4 gene.

The index case (patient 7886 of the Figure 1) is a 52-year-old Caucasian woman, who suffered from microhaematuria, nephrotic range proteinuria $(5.3 \mathrm{~g} / 24 \mathrm{~h})$, arterial hypertension and chronic kidney failure since she was 24 years old. The kidney impairment evolved to end-stage chronic kidney disease at 31 years old. When she was 41 years old, she was diagnosed with high tones sensorineural bilateral hearing loss, and at 42 years old she was also diagnosed with maculopathy. The patient currently has a renal graft.

Her brother (25945 of the Figure 1) is a 53-year-old man who, at 29 years old suffered from an episode of macrohaematuria and edemas. The studies that were carried out showed nephrotic range proteinuria $(8.25 \mathrm{~g} / 24 \mathrm{~h})$ and arterial hypertension. One year later, he developed chronic kidney disease, which evolved towards end-stage chronic kidney failure at 34 years old. At that time, he was admitted into the hemodialysis program. He does not show deafness or ocular impairment.

The father of both patients (27024 of the Figure 1) is an 83-year-old man, diagnosed with sensorineural deafness when he was 67 years old. Eight years later, he was diagnosed with arterial hypertension and chronic kidney disease, with glomerular filtration rate around $40 \mathrm{ml} / \mathrm{min}$, which has remained stable over time. No proteinuria, haematuria or ocular impairment have been observed.

\section{Family 3}

We analyzed one patient, with the pathogenic mutation c.4267C >T; p.P1423S of the COL4A4 gene [11]. The study of the COL4A3 gene did not revealed any pathogenic mutation.

The index case was a 49-year-old woman (patient 23454 of the Figure 1) who, at 6 years old, was diagnosed with high tones sensorineural hearing loss, which progressed to the current need of hearing aid. When she was 28 years old, she showed microhaematuria, 


\section{Kidney \\ Blood Pressure Research}
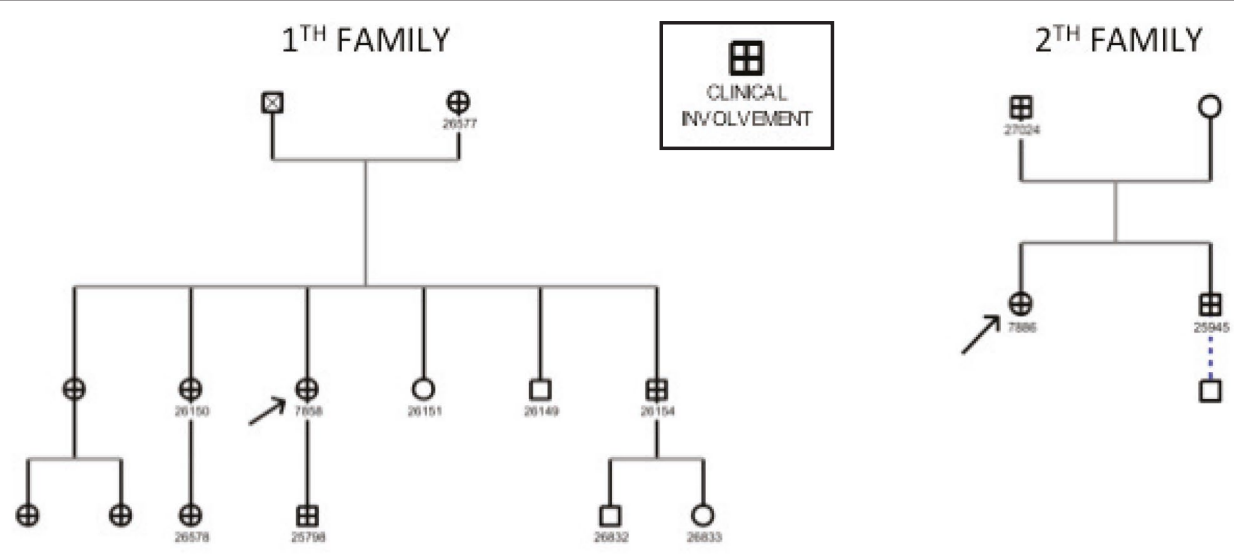

$3^{\text {TH }}$ FAMILY
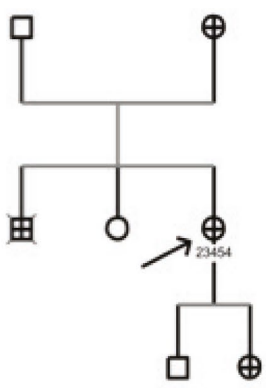

$4^{\text {TH }}$ FAMILY

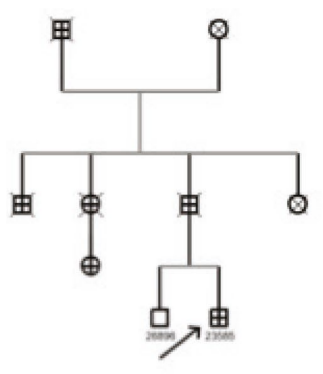

$5^{\text {TH }}$ FAMILY

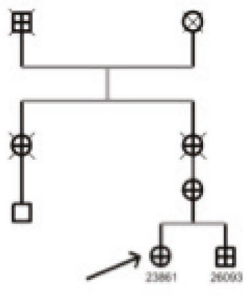

Fig. 1. Family trees of the studied families. Family 1 had lenticonus, hematuria, proteinuria, hearing loss and chronic kidney disease. Family 2 had retinopathy, hematuria, proteinuria, hearing loss and chronic kidney disease. Family 3 had retinopathy, hematuria, proteinuria, hearing loss and chronic kidney disease. Family 4 had hematuria, proteinuria, hearing loss and chonic kidney disease. Family 5 had hematuria, proteinuria, hearing loss and chronic kidney disease.

proteinuria $(0,5 \mathrm{~g} / 24 \mathrm{~h})$ and kidney disease (creatinine clearance of $40 \mathrm{ml} / \mathrm{min}$ ). These symptoms were continuous since then. She showed arterial hypertension at 47 years old and of macular flecks at 48 years old. A renal biopsy was never performed due to the impaired kidney function at the beginning of the study.

Her mother suffered from deafness since a young age, as well as stage III chronic kidney disease, haematuria and proteinuria. Her brother was diagnosed with haematuria, proteinuria and end-stage kidney disease of unknown origin since his adolescence, and he died because of medical complications of the kidney disease. He was never diagnosed with hearing loss or ocular injuries.

The index case's daughter suffered from high tones bilateral sensorineural hearing loss since childhood.

\section{Family 4}

We studied 2 patients who share the pathogenic mutation IVS3 $+1 \mathrm{G}>\mathrm{C}$ of the COL4A4 gene [11]. There were no pathogenic mutations in the COL4A3 gene.

The index case was a 55-year-old man (patient 23585 of the Figure 1) who was diagnosed with arterial hypertension and microhaematuria when he was 30 years old. He developed proteinuria of $0.2 \mathrm{~g} / 24 \mathrm{~h}$ ten years later, which had remained stable. The patient did not develop chronic kidney disease or visual or auditory inpairment.

His father was diagnosed with chronic kidney disease at 75 years old, with creatinine 


\section{Kidney \\ Blood Pressure Research}

Kidney Blood Press Res 2015;40:435-442

\begin{tabular}{l|l}
\hline DOI: $10.1159 / 000368519$ & C 2015 S. Karger AG, Basel \\
\hline
\end{tabular}

Published online: July 31, 2015

www.karger.com/kbr

Rosado/Bueno/Felipe/Valverde/González-Sarmiento: True Clinic of Autosomal Dominant Alport Syndorme

clearance around 30-40 $\mathrm{ml} / \mathrm{min}$ with proteinuria $(0.1 \mathrm{~g} / 24 \mathrm{~h})$ and haematuria. He suffered from arterial hypertension and high tones sensorineural hearing loss since he was 79 years old. He did not show visual impairment.

The paternal family had a large history of sensorineural hearing loss, but we could not study the presence of other signs of Alport syndrome because some of them had passed away and other relatives did not live in the city of the study.

\section{Family 5}

We studied 3 patients, in which we could not find any pathogenic mutation after the analysis of the COLAA3 and COL4A4 genes.

The index case was a 41-year-old woman (figure 23861 of the Figure 1), who has suffered from several episodes of macrohaematuria and microhaematuria since she was 3 years old. At 6 years old, proteinuria of $0.35 \mathrm{~g} / 24 \mathrm{~h}$ was diagnosed, which increased progressively until nephrotic range at 36 years old. At that age she also developed hypertension and chronic kidney disease, when she was pregnant. She entered a haemodialysis program at 39 years old. Nowadays she has a renal graft. A renal biopsy was performed at 22 years old, which showed the lamination of the glomerular basement membrane. The presence of high tones sensorineural hearing loss was established when she was 8 years old. She did never show any ocular impairment.

Her brother was a 33-year-old man diagnosed with macrohaematuria and nephrotic range proteinuria when he was 9 months old. He developed chronic kidney disease when he was 14 years old and he entered a program of peritoneal dialysis 5 years later. He was diagnosed with sensorineural hearing loss when he was one year old. He had no shown any ocular impairment. Their mother suffered from microhaematuria, non-nephrotic proteinuria, arterial hypertension, grade III chronic kidney disease and sensorineural hearing loss since her adolescence. The patient's maternal great-grandparent died when he was 20 years old. He suffered from sensorineural hearing loss and chronic kidney disease, and so did his two daughters (the patient's grandmother and aunt). The presence of haematuria, proteinuria or ocular impairment in these patients could not be determined because they had all passed away.

The family data suggested the existence of ADAS, but we could not find any pathogenic mutation after sequencing 43 exons of the COL4A3 gene and 21 exons of the COL4A4 gene, but the findings in the renal biopsy made us make the diagnosis of Alport syndrome.

Table 1 shows all the symptoms of the studied patients. The analysis of the different clinical parameters revealed that the most common injury in our series was hearing loss, followed by chronic kidney disease, proteinuria and haematuria, as can be seen in Table 2 . The onset age of the different symptoms is detailed in Table 3.

The median value of proteinuria was $1.58 \mathrm{~g} /$ day (0.22-5.05), and the maximum value reached was $2.06(0.29-6.97)$. Only 4 out of 19 patients $(21 \%)$, belonging to $2^{\text {th }}$ and $5^{\text {th }}$ families, reached a nephrotic range of proteinuria. Between our 19 patients, only $8(42,1 \%)$ suffered from haematuria, and 6 of them $(75 \%)$ had episodes of gross haematuria (families $1,2,3$ and 5). All of our patients were treated with inhibitors of the renin-angiotensin II-aldosterone system.

\section{Discussion}

We have studied 5 families with autosomal dominant Alport syndrome. This diagnosis has been suspected by the study of the family record and confirmated by genetic study or by the finding of compatible injuries in glomerular basal membrane [12].

The genetic study method we have performed has been the heteroduplex with acrylamide gels. Although the most accurate genetic method for the diagnosis of Alport syndrome is MPS, we could not use it because our laboratory did not have it. Nevertheless, we 


\section{Kidney \\ Blood Pressure Research}

Table 1. Clinical and laboratory data of the studied patients

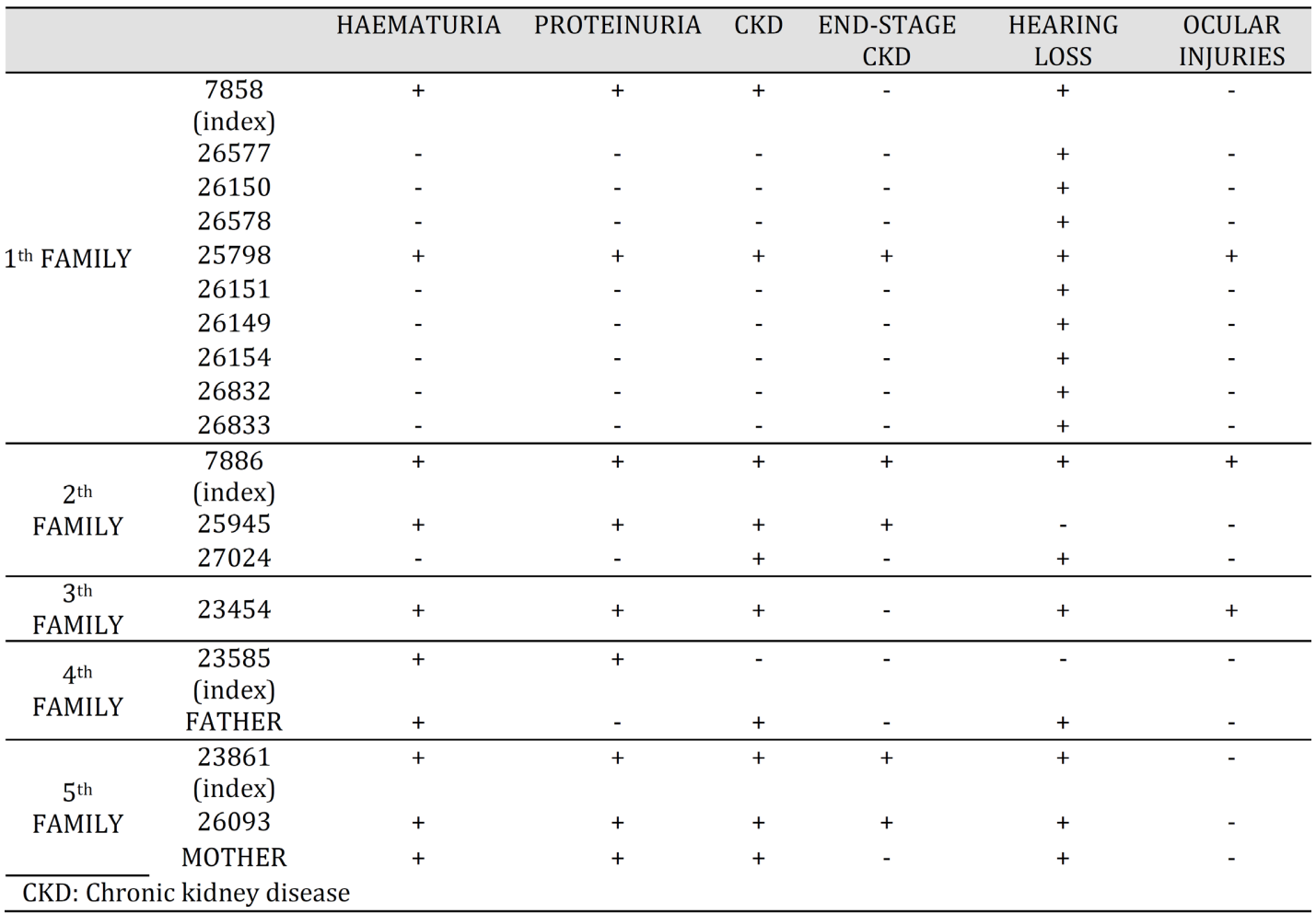

can ensure that these families suffer from autosomal dominant Alport syndrome, since we have studied the two genes and we have been able to exclude a second mutation in every patient. Besides, all the mutations responsible for the illness in our families are pathogenic mutations (frameshift, splicing and missense), described in different works $[1,10$, 11].

This certain diagnosis of autosomal dominant Alport syndrome makes us reject another diseases, like thin membrane nephropathy with superimposed IgA glomerulonephritis.

Autosomal dominant Alport syndrome is characterized by a late onset age, between 40 and 60 years $[6,7]$; however, the patients included in our sample had a relatively early median age at the moment of the diagnosis of the disease, around 29 years, and similar to what has been observed in other inheritance patterns. Haematuria and proteinuria were the renal signs of onset in most of our patients, which suggests that they must become an alert sign in the diagnosis of Alport syndrome, both for the general practitioner and for the nephrologist $[13,14]$, even when the patient does not present a positive family record, in order to reach an early diagnosis which, with an adequate
Table 2. Frequency of different clinical manifestations

\begin{tabular}{lcc}
\hline CLINICAL PARAMETER & TOTAL & AT DIAGNOSIS \\
\hline CKD & $9(47,4 \% 9$ & $6(31,6 \%)$ \\
End stage ckd & $5(26,3 \%)$ & 0 \\
Haematuria & $8(42,1 \%)$ & $8(42,1 \%)$ \\
Proteinuria & $9(47,4 \%)$ & $8(42,1 \%)$ \\
Hypertension & $9(47,4 \%)$ & $6(31,6 \%)$ \\
Hearing loss & $13(68,4 \%)$ & $9(47,4 \%)$ \\
Ocular involvement & $3(15,8 \%)$ & $2(10,5 \%)$ \\
\hline
\end{tabular}

Table 3. Age of onset of the different symptoms

\begin{tabular}{cc}
\hline SYMPTOM & AGE OF ONSET (years) \\
\hline Haematuria & $15(2,25-28,75)$ \\
Proteinuria & $28(6-36)$ \\
CKD & $30(21,5-55,5)$ \\
Progression to end stage CKD & $4(3-6)$ \\
End stage CKD & $31(20,5-36,5)$ \\
Hypertension & $32(26,5-61)$ \\
Hearing loss & $28,5(7,5-62,5)$ \\
Ocular involvement & $42(9-48)$ \\
Clinical diagnosis & $29(4-61)$ \\
\hline
\end{tabular}




\section{Kidney Blood Pressure Research}

Kidney Blood Press Res 2015;40:435-442

\begin{tabular}{l|l}
\hline DOI: $10.1159 / 000368519$ & C 2015 S. Karger AG, Basel
\end{tabular}

Published online: July 31, 2015

www.karger.com/kbr

441

therapeutic measures, such as inhibitors of the renin-angiotensin II-aldosterone system [9], could, in some cases, delay the impairment of renal function and improve prognosis [15, 16]. Proteinuria appeared at a relatively early age (in the third decade of life), but later than haematuria, probably because these patients (who presented this sign in the beginning of their disease) were diagnosed in advanced stages, when the renal damage was already clear. In our study, proteinuria did not reach a nephrotic range, which matches what has been described in other series [2].

Chronic kidney disease appeared in a high number of patients, and it presented a relatively early onset. The reason for the high prevalence of the impairment of renal function in our series can be due to the fact that haematuria and proteinuria appeared in relatively early ages and contributed to the fast establishment and progression of the renal disease, and also to the fact that the diagnosis was established late, once the renal damage had already been established. The high prevalence of hypertension at diagnosis in our series might be the result of the fact that the disease was diagnosed at an advanced age. There are no data in the literature on the prevalence of this sign in Alport syndrome, regardless of its inheritance pattern, and it is considered a late feature associated to renal failure [6], which matches our results.

The appearance of ocular and hearing injuries is not usually predominant in autosomal dominant patterns of Alport syndrome, which represents a difference compared with the recessive and sex-linked patterns $[14,17,18]$. Bilateral sensorineural high tones hearing loss was an early onset symptom in our series, and it was present in most of the patients. Its real prevalence is unknown, because audiometries are not common practice [18]. However, it is necessary to emphasize the importance of taking this symptom as a key factor in the diagnosis of the disease in cases of nephropathies accompanied by haematuria and proteinuria, because its presence in these cases is highly suggestive of this genetic disorder [10]. Hearing loss is observed in late infancy or adolescence in patients with recessive and $\mathrm{X}$ chromosome-linked patterns, whereas in the cases with a dominant inheritance pattern it appears in adult age $[2,19,20]$. However, our patients were diagnosed with hearing loss at an early age (before 30 years), which can be explained by the high clinical variability presented by this inheritance pattern [1]. In our series we found patients with ocular injuries, such as lenticonus, which until now had only been described in recessive and sex-linked inheritance patterns $[10,14,17,20]$.

\section{Conclusion}

Our results reflect the high variability in the clinical expression of autosomal dominant Alport syndrome, and they reveal that this illness is not as benign as it was traditionally thought. Instead, it can behave similarly to the recessive or X-linked disease. Until now, there is not a clear explanation for this great variability, but there are some hypothesis who affirm that mutations in other genes of the glomerular basal membrane, who encode different proteins such as laminin, podocin, integrins or metalloproteases could modulate the phenotypic expression of the COL4A3 or COL4A4 mutations in some patients, who would suffer a more severe illness, while their relatives, who only suffer the COL4A3 or COL4A4 mutations, would suffer a milder disease $[10,11]$.

A possible consequence of this may be that patients with autosomal dominant Alport syndrome with severe symptoms are erroneously labeled as patients with a recessive inheritance pattern because their relatives may show such mild symptoms that they are never diagnosed, due to the high phenotypic variability of this condition. This fact makes it difficult to reach an adequate diagnosis for this condition and to assign a well-defined inheritance pattern to the families. This leads us to suggest that dominant patterns are undiagnosed, which means that their real prevalence may be higher than the $5 \%$ of all Alport syndrome cases that are classically described. 


\section{Kidney \\ Blood Pressure Research}

\section{Disclosure Statement}

All authors declare no conflicts of interest. Dominant Alport Syndorme
Kidney Blood Press Res 2015;40:435-442

\begin{tabular}{l|l}
\hline DOI: 10.1159/000368519 & (c) 2015 S. Karger AG, Basel
\end{tabular}

Published online: July 31, 2015

www.karger.com/kbr

Rosado/Bueno/Felipe/Valverde/González-Sarmiento: True Clinic of Autosomal

\section{References}

1 Tazón Vega B, Badenas C, Ars E, Lens X, Milà M, Darnell A, Torra R: Autosomal recessive Alport's syndrome and benign familial hematuria are collagen type IV diseases. Am J Kidney Dis 2003;42:952-959.

2 Tazón B, Ars E, Torra R: The Alport Syndrome. Nefrologia 2003;23:S29-S39.

3 Cosgrove D: Glomerular pathology in Alport syndrome: a molecular perspective. Pediatr Nephrol 2012;27:885-890.

4 Badenas C, Praga M, Tazón B, Heidet L, Arrondel C, Armengol A, Andrés A, Morales E, Camacho JA, Lens X, Dávila S, Milà M, Antignac C, Darnell A, Torra R: Mutations in the COL4A4 and COL4A3 genes cause familial benign hematuria. J Am Soc Nephrol 2002;13:1248-1254.

5 Hudson BG: The molecular basis of Goodpasture and Alport syndromes: beacons for the discovery of the collagen IV family. J Am Soc Nephrol 2004;15:2514-2527.

6 Pirson Y: Making the diagnosis of Alport syndrome. Kidney Int 1999;56:760-775.

7 Savige J, Gregory M, Gross O, Kashtan C, Ding J, Flinter F: Expert guidelines for the management of Alport syndrome and thin basement membrane nephropathy. J Am Soc Nephrol 2013;24:364-375.

8 Gubler MC: Diagnosis of Alport syndrome without biopsy? Pediatr Nephrol 2007;22:621-625.

9 Fallerini C, Dosa L, Tita R, Del Prete D, Feriozzi S, Gai G, Clementi M, La Manna A, Miglietti N, Mancini R, Mandrile G, Ghiggeri GM, Piaggio G, Brancati F, Diano L, Frate E, Pinciaroli AR, Giani M, Castorina P, Bresin E, Giachino D, De Marchi M, Mari F, Bruttini M, Renieri A, Ariani F: Unbiased next generation sequencing analysis confirms the existence of autosomal dominant Alport syndrome in a relevant fraction of cases. Clin Genet 2014;86:252-257.

10 Rosado C, Bueno E, Fraile P, García-Cosmes P, González-Sarmiento R: A new mutation in the COL4A3 gene responsible for autosomal dominant Alport syndrome, which only generates hearing loss in some carriers. Eur J Med Genet 2015;58:35-38.

11 Rosado C, Bueno E, Felipe C, Gonzalez-Sarmiento R: COL4A4 gene study in a European population. Description of new mutations causing autosomal dominant Alport syndrome. Int J Mol Epidemiol Genet 2014;5:177-184.

12 Miner JH, Baigent C, Flinter F, Gross O, Judge P, Kashtan CE, Lagas S, Savige J, Blatt D, Ding J, Gale DP, Midgley JP, Povey S, Prunotto M, Renault D, Skelding J, Turner AN, Gear S: The 2014International Workshop on Alport Syndrome. Kidney Int 2014;86:679-684.

13 Kashtan CE: Familiar hematuria. Pediatr Nephrol 2009;24:1951-1958.

14 Izzedine H, Tankere F, Launay-Vacher V, Deray G: Ear and kidney syndromes: molecular versus clinical approach. Kidney Int 2004;65:369-385.

15 Webb NJ, Lam C, Shahinfar S, Strehlau J, Wells TG, Gleim GW, Le Bailly De Tilleghem C: Efficacy and safety of losartan in children with Alport syndrome. Results from a subgroup analysis of a prospective, randomized, placebo-or amlodipine-controlled trial. Nephrol Dial Transplant 2011;26:2521-2526.

16 Temme J, Peters F, Lange K, Pirson Y, Heidet L, Torra R, Grunfeld JP, Weber M, Licht C, Müller GA, Gross $\mathrm{O}$ : Incidence of renal failure and nephroprotection by RAAS inhibition in heterozygous carriers of X-chromosomal and autosomal recessive Alport mutations. Kidney Int 2012;81:779-783.

17 Seymenoğlu G, Baser EF: Ocular manifestations and surgical results in patients with Alport syndrome. J Cataract Refract Surg 2009;35:1302-1306.

18 Thodi C, Thodis E, Danielides V, Pasadakis P, Vargemezis V: Hearing in renal failure. Nephrol Dial Transplant 2006;21:3023-3030.

19 Marcocci E, Uliana V, Bruttini M, Artuso R, Silengo MC, Zerial M, Bergesio F, Amoroso A, Savoldi S, Pennesi M, Giachino D, Rombolà G, Fogazzi GB, Rosatelli C, Martinhago CD, Carmellini M, Mancini R, Di Costanzo G, Longo I, Renieri A, Mari F: Autosomal dominant Alport syndrome: molecular analysis of the COL4A4 gene and clinical outcome. Nephrol Dial Transplant 2009;24:1464-1471.

20 Hanson H, Storey H, Pagan J, Flinter F: The value of clinical criteria in identifying patients with X-linked Alport syndrome. Clin J Am Soc Nephrol 2011;6:198-203. 